Research Article

\title{
To study cost effectiveness of topical permethrin versus oral ivermectin in patients of uncomplicated scabies
}

\author{
Sunita B. Chhaiya ${ }^{1}$, Varsha J. Patel ${ }^{3}$, Jayendra N. Dave ${ }^{2}$, Dimple S. Mehta ${ }^{1}$
}

${ }^{1}$ Department of Pharmacology,

${ }^{2}$ Department of Dermatology, C. U. Shah Medical College, Surendranagar, Gujarat, India ${ }^{3}$ Department of Pharmacology, NHL Municipal Medical College, Ahmedabad, Gujarat, India

Received: 25 October 2013

Accepted: 27 October 2013

*Correspondence to:

Dr. Sunita B. Chhaiya,

Email:

s_chhaiya@rediffmail.com

(C) 2013 Chhaiya SB et al. This is an open-access article distributed under the terms of the Creative Commons Attribution Non-Commercial License, which permits unrestricted non-commercial use, distribution, and reproduction in any medium, provided the original work is properly cited.

\begin{abstract}
Background: The objective of this study was to compare the cost and effectiveness of topical permethrin and oral ivermectin in the treatment of uncomplicated scabies.

Methods: This was an open label randomized comparative study conducted in 210 patients, randomly allocated to two groups. First group received permethrin $5 \%$ cream as single application, second group received tablet ivermectin $200 \mathrm{mcg} / \mathrm{kg}$ as single dose. All the patients received antihistaminic for pruritus. The patients were followed up at intervals of one, two, three and four weeks. If there were no signs of cure, the same intervention was repeated at each follow up. The cost effectiveness was calculated on the basis of total expenditure incurred on therapy.

Results: At the end of first week cure rate was $74.8 \%$ in permethrin group, $30 \%$ in oral ivermectin group. At the end of second week cure rate was $99 \%$ in permethrin group, $60 \%$ in oral ivermectin group. At the end of third week $100 \%$ cure rate was observed in permethrin while $99 \%$ in oral ivermectin group. The total cost of treatment shows that cost of tab. ivermectin was less compared to permethrin $5 \%$ but the cost to relieve itching and cost of transport was higher than permethrin $5 \%$.

Conclusions: Topical permethrin is more cost effective than oral ivermectin in treatment of uncomplicated scabies.
\end{abstract}

Keywords: Scabies, Permethrin, Ivermectin

\section{INTRODUCTION}

Scabies is a common parasitic infection caused by the mite Sarcoptes scabiei var homnis. It is a major global health problem in many indigenous and third world communities. ${ }^{1}$ It has been estimated that 300 million people suffer from scabies infestation at any one time. Scabies is an important disease of children, but it occurs in both sexes at all ages, in all ethnic groups and all socioeconomic levels. ${ }^{2}$ Different therapies for scabies consist of topical antiscabietics such as precipitated sulphur, crotamiton, lindane and permethrin. At present permethrin $5 \%$ has become the antiscabietic of choice in United States because of report of resistance to and central nervous system toxicity to lindane. ${ }^{3}$ Ivermectin is an antiparasitic agent effective against a variety of endoparasites and ectoparasites. ${ }^{4}$ Initial reports have highlighted the utility of oral ivermectin in the treatment of scabies. ${ }^{5-8}$ Hence this clinical study was planned and conducted to know the cost effectiveness of topical permethrin and oral ivermectin in Indian population for treatment of scabies.

\section{METHODS}

This was an open label randomized comparative clinical study. The study was approved by the institutional ethics committee. The study was carried out in the Department of Pharmacology in collaboration with outpatient Department of Dermatology of C. U. Shah Medical College and hospital, Surendranagar, Gujarat, India. From June 2007 to January 2009, the patients willing to 
participate were enrolled in the study. Sample size was calculated by using sample size calculator (Raosoft, 2004). The enrolled participants were randomised according to random allocation number generated through computer by using complete randomized design to any one of the two groups with help of inclusion and exclusion criteria.

\section{Inclusion criteria}

1. Patients of either sex aged 5 to 80 years with clinically diagnosed scabies, 2. Presence of typical scabietic lesions like papules, nodules or vesicles at classical sites, 3 . Presence of classical burrows on clinical examination, 4. Nocturnal pruritus, 5. History of involvement of family member or similar symptoms in contacts, 6 . Microscopically diagnosed scabies (demonstration of egg, larvae, mite or faecal material), 7. Patients whose microscopic examination was negative, their inclusion in study was based on clinical criteria, for that patient had to satisfy at least three out of four inclusion criteria (inclusion criteria no. 2 to 5), 8. Patients who were willing to participate and to give written informed consent.

\section{Exclusion criteria}

1. Patient treated with any topical scabicidal therapy in the month before entry, 2. Patients taking any topical or systemic antibiotic therapy in the week before entry into the study, 3. Immunologically compromised patients, 4. Having scabies with atypical presentation like crusted scabies or scabies incognito, 5. Patients with secondary bacterial infection, 6. History of allergy to any of the study drugs, 7. Blood pressure <100/60mm Hg, 8. Pregnancy in women and lactating mothers.

Severity of lesions was clinically graded on a scale of 0 to 3. Grade 0 - free of lesions (no lesions), Grade 1 - 10 or fewer lesions (mild), Grade 2 - 11 to 49 lesions (moderate), Grade 3 - 50 or more lesions (severe). Itching was graded on a scale of 0 to 3 on basis of severity. Grade 0 - no itching, Grade 1 - mild itching, Grade 2 - moderate itching, Grade 3 - severe/ intense itching.

\section{Interventions}

\section{Permethrin 5\% Cream}

Permethrin 5\% cream was supplied by Shalaks Pharmaceutical Ltd. New Delhi. It is available as 30 gram tube. The commercially available permethrin Scabper $^{\mathrm{TM}}$ 30 gram cream, carton covered, capped aluminium tube is priced at $₹ 41$. The patients included in this group were given permethrin 5\% cream along with printed information sheet in the local vernacular language. They were asked to apply the cream to whole body covering neck to toe. They were explained that the cream must remain in contact with the skin for at least 8 hours. They were advised to take bath with warm water not earlier than 8 hours after application.

\section{Tablet ivermectin}

Tablet ivermectin was supplied by Shalaks Pharmaceutical Ltd. New Delhi. The commercially available ivermectin Ivecop ${ }^{\mathrm{TM}}$ supplied in carton covered blister pack of single tablet, is available in strengths of $3 \mathrm{mg}$, priced at $₹ 6 ; 6 \mathrm{mg}$, priced at $₹ 10$ and $12 \mathrm{mg}$ tablet, priced at $₹ 18$. The patients included in this group were given tablet ivermectin orally in the dose of $200 \mathrm{mcg} / \mathrm{kg}$, as a single dose to be self administered along with printed information sheet in the local vernacular language.

\section{Antihistaminic}

All patients received Tab. hydroxyzine $10 \mathrm{mg}$ priced at ₹ 7 per ten tablets or $25 \mathrm{mg}$ priced at ₹ 13 per ten tablets. It was advised twice daily for symptomatic treatment of pruritus.

\section{Assessment of patients}

Patients were followed up at the end of first, second, third and fourth week to assess compliance and examine the patient to evaluate efficacy and safety. Primary end point was clinical cure of scabietic lesions and Secondary end point was complete relief of pruritus. At each of the four visits examination of the entire body surface was performed. All remaining suspected scabies lesions were examined and compared with baseline clinical grading score and itching grading score. The patients were asked for any adverse event occurring during previous week. The cured participants were prescribed antihistaminic for further one week if itching grade was severe or moderate. If the patients had mild itching, no antihistaminic was prescribed. The participants who were not cured were prescribed repeat intervention along with antihistaminic. All the participants were again called for follow up visit after one week. The participants who were not cured at the end of third week were switched over to standard treatment with $5 \%$ permethrin. Statistical analysis was done by using SPSS version 12.0. Differences in proportions were compared with the Chi square statistic. Statistical analysis of efficacy was done by Chi square test and one way ANOVA test. $\mathrm{P}$ values $<0.05$ were considered significant.

\section{Cost effectiveness}

The cost effectiveness was calculated on the basis of total expenditure incurred on medicines plus cost to relieve itching and cost of transport at the end of four weeks in ₹ and cure rate in percentage. The cost of transport was calculated at ₹ 40 per visit on the basis of average cost for follow up visit from nearby village or town.

Total cost of treatment $=$ cost in ₹ for participants cured with one week treatment + cost in ₹ for participants cured 
with second week treatment + cost in ₹ for participants cured with third week treatment + cost in ₹ for participants cured at the end of fourth week.

Incremental cost $(\Delta \mathrm{C})=$ Cost of the new $(\mathrm{Tab}$. Ivermectin) treatment - Cost of the old (Permethrin5\%) treatment.

Incremental effectiveness $(\Delta \mathrm{E})=$ Efficacy of new (second) treatment - Efficacy of old (first) treatment. ${ }^{9}$

\section{RESULTS}

Total 210 patients were enrolled in the study and randomly allocated to two treatment groups. 11 failed to report for follow up after the initial treatment. Out of these 6 received permethrin cream 5\%, 5 received tab. ivermectin. Those patients, who failed to follow up, were excluded from the study for further analysis. Patients were failed to follow up it may be due to complete cure or due to no improvement in clinical condition. There was no significant difference between the two study groups at baseline in demographic and clinical characteristics (Table 1).

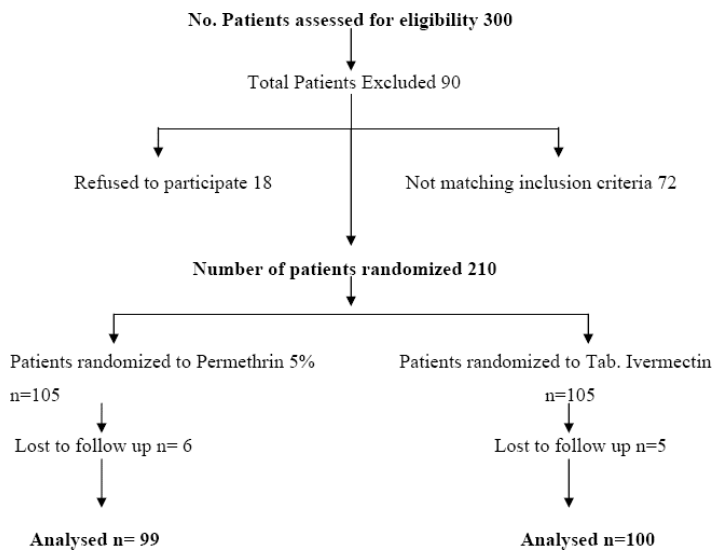

Figure 1: Flow chart of patients in the study.

Table 1: Baseline characteristics of three treatment groups.

\begin{tabular}{|ll|l|}
\hline & $\begin{array}{l}\text { Permethrin } \\
\mathbf{5 \%} \mathbf{n}=\mathbf{1 0 5}\end{array}$ & $\begin{array}{l}\text { Tab. } \\
\text { Ivermectin } \\
\mathbf{n = 1 0 5}\end{array}$ \\
\hline Age (mean \pm SD) & $\begin{array}{l}23.40 \pm \\
13.55\end{array}$ & $\begin{array}{l}21.97 \pm \\
13.26\end{array}$ \\
\hline Gender(Male/Female) & $58 / 47$ & $58 / 47$ \\
\hline Family History (\%) & 89.5 & 87.6 \\
\hline Lab. Diagnosis (\%) & 19 & 24.8 \\
\hline Nocturnal pruritus (\%) & 100 & 100 \\
\hline Severity of disease: & & \\
\hline Severe/moderate/mild/no & $13.1 / 36.4 /$ & $19 / 39 / 38 / 4$ \\
lesions (\%) & $46.5 / 4$ & \\
\hline
\end{tabular}

Clinical cure rate at different visits shows that there is significant difference between tablet ivermectin group and permethrin groups up to two weeks $(p<0.05)$. At the end of third week there was no statistically significant difference between the two groups ( $p=0.367)$. Cost of antiscabies medicine, cost of antihistaminic and cost of conveyance at different visits is shown in Tables 2, 3 and 4 respectively. Total cost of therapy in permethrin $5 \%$ group was ₹ 18852.8 while in tab. ivermectin group was ₹ 20360. So cost per patient was ₹ 189 for permethrin $5 \%$ and ₹ 204 for tab. ivermectin. Cost effectiveness of two treatments is shown in Table 5. Cost effectiveness of tab. ivermectin in comparison with permethrin $5 \%$ suggests that cost of tab. ivermectin is higher and effectiveness is less compared to permethrin $5 \%$ and thus lies in unacceptable zone (Figure 2).

Table 2: Cost of medicines at different follow up visits.

\begin{tabular}{|c|c|c|}
\hline & $\begin{array}{l}\text { Permethrin } 5 \% \\
\text { n }=99 \\
\left(\text { Cost }^{*} \times \text { Cure }\right. \\
\text { rate } * *)\end{array}$ & $\begin{array}{l}\text { Tab. } \\
\text { Ivermectin } \\
\mathbf{n}=100 \\
(\text { Cost* } \times \text { Cure } \\
\left.\text { rate }^{* * *}\right)\end{array}$ \\
\hline $1^{\text {st }}$ week & $41 \times 74.8=3066.8$ & $18 \times 30=540$ \\
\hline $2^{\text {nd }}$ week & $82 \times 24.2=1984.4$ & $36 \times 33=1188$ \\
\hline $3^{\text {rd }}$ week & $123 \times 1=123$ & $54 \times 36=1944$ \\
\hline $\begin{array}{l}\text { Total cost of } \\
\text { medicine }\end{array}$ & 5174.2 & 3672 \\
\hline
\end{tabular}

*Cost- in ₹** Percentage cured

Table 3: Cost of antihistaminics at different follow up visit.

\begin{tabular}{|lll|}
\hline & $\begin{array}{l}\text { Permethrin 5\% } \\
\mathbf{n}=99 \\
(\text { Cost** Cure } \\
\text { rate**) }\end{array}$ & $\begin{array}{l}\text { Tab. Ivermectin } \\
\mathbf{n}=100 \\
\left(\text { Cost }^{* *} \times \text { Cure }\right. \\
\left.\text { rate }^{* *}\right)\end{array}$ \\
\hline $1^{\text {st }}$ week & $14 \times 23.2=324.8$ & $14 \times 3=42$ \\
\hline $2^{\text {nd }}$ week & $28 \times 67.7=1895.6$ & $28 \times 44=1232$ \\
\hline $3^{\text {rd }}$ week & $42 \times 9.1=382.2$ & $42 \times 51=2142$ \\
\hline $4^{\text {th }}$ week & - & $56 \times 2=112$ \\
\hline $\begin{array}{l}\text { Total cost of } \\
\text { antihistaminics }\end{array}$ & 2602.6 & 3528 \\
\hline
\end{tabular}

*Cost in ₹** Percentage cured 
Table 4: Cost of transport at different follow up visits.

$\left.\begin{array}{|lll|}\hline & \begin{array}{l}\text { Permethrin 5\% } \\ \mathbf{n}=99 \\ \left(\text { Cost }^{*} \times \text { Cure }\right. \\ \text { rate**) }\end{array} & \begin{array}{l}\text { Tab. } \\ \text { Ivermectin } \\ \mathbf{n}=100 \\ \left(\text { Cos }^{*} \text { t } \times \text { Cure }\right. \\ \text { rate }\end{array}\end{array}\right)$

*Cost in ₹** Percentage cured

Table 5: Cost effectiveness of tab. ivermectin compared with permethrin $5 \%$.

\begin{tabular}{|llll|}
\hline & $\begin{array}{l}\text { Permethrin } \\
\mathbf{5 \%}\end{array}$ & $\begin{array}{l}\text { Tab. } \\
\text { Ivermectin }\end{array}$ & \\
\hline Cost in ₹ & 189 & 204 & $\Delta \mathrm{C}=15$ \\
\hline $\begin{array}{l}\text { Effectiveness } \\
(\%)\end{array}$ & 100 & 99 & $\Delta \mathrm{E}=-1$ \\
\hline
\end{tabular}

$\Delta \mathrm{C}=$ Cost of Tab. Ivermectin - Cost of Permethrin $5 \%$

$\Delta \mathrm{E}=$ Efficacy of Tab. Ivermectin - Efficacy of Permethrin 5\%

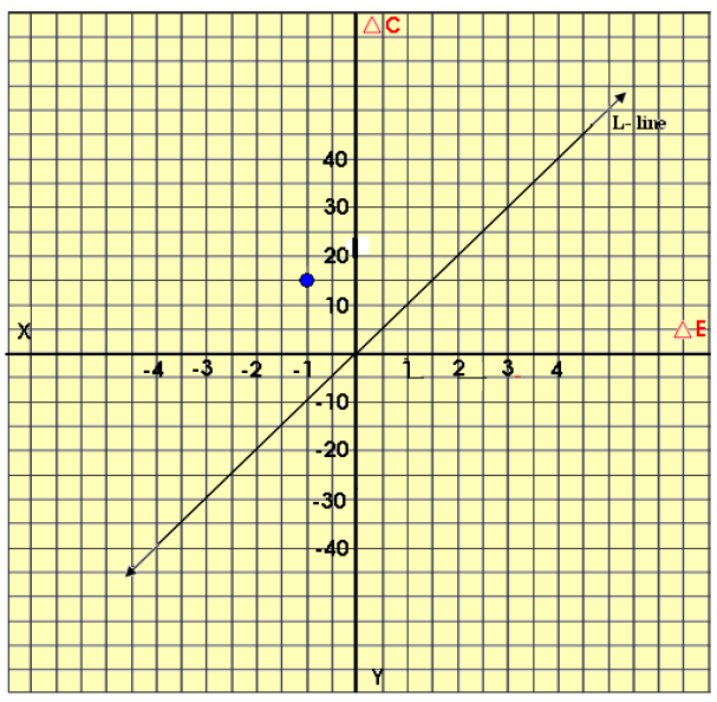

\section{Figure 2: Cost effectiveness of oral ivermectin compared with permethrin cream.}

Figure 2, $\mathrm{X}$-axis shows $\Delta \mathrm{E}$, that is, incremental effectiveness, $\mathrm{Y}$-axis shows $\Delta \mathrm{C}$, that is, incremental cost, and L-line is the arbitrary line differentiating between the zones (zone above the L-line is unacceptability zone and zone below the line is acceptability zone). Blue dot is for tab. ivermectin in comparison with permethrin $5 \%$ cream.

\section{DISCUSSION}

The limiting factor in the wide use of any drug is its high cost. In a study on cost benefit and safety analysis of antiscabietic drugs, permethrin $5 \%$ was claimed to be the best option for scabies in infants and young children. ${ }^{10} \mathrm{~A}$ recent study from India carried out cost effective analysis of three treatments benzyl benzoate, permethrin and oral ivermectin and concluded benzyl benzoate for two weeks as the most cost effective therapy. However antihistaminics were not used in the first week of study and the cost of antihistaminic and transport expenses were not included in total cost. ${ }^{11}$ Morbidity related to itching (pruritus) is such a common symptom that patients scratch their lesions almost constantly. Repeated scratching of a lesion causes excoriation and denudation of the skin thus creating portals of entry for pathogenic bacteria. The clinical consequences of secondary bacterial infection, especially with group A streptococci, result in significant, frequently unrecognized illnesses, such as cellulitis, boils, pyomyositis. ${ }^{12}$ Hence cost can be better considered on the basis of relief of pruritus and thus the cost of antihistaminics was added in our study as direct cost of therapy.

In the present study hydroxyzine was used for pruritus. Hydroxyzine enter the skin readily and sustained high concentration in skin may contribute high efficacy in skin disorder. $^{13}$ Patients with scabies presented with generalized itching, which is frequently reported to be more intense at night, so it may disturbed patients sleep. Hydroxyzine is first generation antihistaminic having sedative action.

In the present study economic analysis shows that the cost of treatment with permethrin 5\% was higher compared to tab. ivermectin. We included cost of antihistaminic which is given to relieve pruritus because primary symptom of scabies is itching. If the symptoms of disease were not relieved with single administration of drug, the number of follow up visits increased. Hence in calculation of cost of therapy the total expense of transport was also included. Looking to the cost analysis, although permethrin $5 \%$ is priced higher compared to tab. ivermectin, the additional cost of antihistaminic and transport was less due to earlier response with permethrin. As tab. ivermectin had lower cure rate at the first visit compared to other two treatments, the number of visits increased and that increased the cost of therapy of tab. ivermectin.

Repeating the treatment every week achieves higher cure rate with oral ivermectin because ivermectin has not been proven to be ovicidal a single dose of $200 \mathrm{mcg} / \mathrm{kg}$ body weight may be inadequate to eradicate the different stages of the parasites and a higher dose or a second dose may be required within one or two weeks for $100 \%$ cure rate. ${ }^{14}$ 
A previous study also showed that oral ivermectin was less effective in relieving pruritus as compared to permethrin. $^{11}$ A drug with a faster effect in relieving pruritus is much more acceptable to patients. Moreover such drug will also reduce the requirement of antihistaminic.

In both the treatment groups, no severe/serious adverse events were observed. Only three patients had mild adverse events- mild burning sensation in permethrin group, headache and increase in pruritus in oral ivermectin group suggesting no difference in tolerability between the two treatments. We have included only uncomplicated cases in our study. Hence the findings can not be extrapolated to complicated and other variants of scabies.

\section{CONCLUSION}

From this study it can be concluded that topical permethrin is more cost effective than oral ivermectin in treatment of uncomplicated scabies.

\section{Funding: None}

Conflict of interest: None declared

Ethical approval: The study was approved by the Institutional Ethics Committee

\section{REFERENCES}

1. Scheinfeld N. Controlling scabies in institutional settings: a review of medications, treatment models, and implementation. Am $\mathrm{J}$ Clin Dermatol 2004;5:31-7.

2. Taplin D, Meinking TL. Pyrethrins and pyrethroids in dermatology. Arch Dermatol 1990b;126:213-21.

3. Tracy WJ, Webster LT. Drugs used in the chemotherapy of helminthiasis. In, Hardman JG, Limbird LE. Goodman Gilman's The pharmacological basis of medical therapeutics, 11th edition. New York, McGraw Hill. 2007;1009-26.
4. Campbell WC. Ivermectin, an antiparasitic agent. Med Res Rev 1993;13:61-79.

5. Glaziou P, Cartel JL, Alzieu P, Briot C, MouliaPelat JP, Martin PM. Comparison of ivermectin and benzyl benzoate for treatment of scabies. Trop Med Parasitol 1993;44:331-2.

6. Macotela-Ruíz E, Peña-González G. The treatment of scabies with oral ivermectin. Gac Med Mex 1993;129:201-5.

7. Chouela EN, Abeldaño AM, Pellerano G, La Forgia M, Papale RM, Garsd A, et al. Equivalent therapeutic efficacy and safety of ivermectin and lindane in the Treatment of Human Scabies. Arch Dermatol 1999;135:651-5.

8. Usha V, Gopalakrishnan Nair TV. A comparative study of oral ivermectin and topical permethrin cream in the treatment of scabies. J Am Acad Dermatol 2000;42:236-40.

9. Heitjan DF, Moskowitz AJ, and Whang W. Bayesian estimation of cost- effectiveness ratios from clinical trials. Health Econ. 1999;8:191-201.

10. Elgart ML. Cost-benefit analysis of ivermectin, permethrin and benzyl benzoate in the management of infantile and childhood scabies. Expert Opin Pharmacother. Sep 2003;4(9):1521-4.

11. Bachewar NP, Thawani VR, Mali SN, Gharpure KJ, Shingade VP, Dakhale GN. Comparison of safety, efficacy, and cost effectiveness of benzyl benzoate, permethrin, and ivermectin in patients of scabies. Indian J Pharmacol 2009;41:9-14.

12. Feldmeier H Epidermal parasitic skin diseases: a neglected category of poverty-associated plagues. Bull World Health Organ 2009;87:152-159.

13. Simons FE, Murray HE, Simons KJ Quantitation of H1 antagonists in skin and serum. J Allergy Clin Immunol 1995;95(3):759-64.

14. Ly F, Caumes E, Ndaw CA, Ndiaye B, Mahé A. Ivermectin versus benzyl benzoate applied once or twice to treat human scabies in Dakar, Senegal: a randomized controlled trial. Bull World Health Organ 2009;87:424-30.

doi:10.5455/2319-2003.ijbcp20131224

Cite this article as: Chhaiya SB, Patel VJ, Dave JN, Mehta DS. To study cost effectiveness of topical permethrin versus oral ivermectin in patients of uncomplicated scabies. Int J Basic Clin Pharmacol 2013;2:799-803. 